\title{
DESTILAÇÃO DA MICELA I: MODELAGEM E SIMULAÇÃO DA EVAPORAÇÃO DO HEXANO'
}

\author{
Paulo R. PARAÍSO ${ }^{2, *}$, Cid M. G. ANDRADE ${ }^{2}$, Roger J. ZEMP ${ }^{3}$
}

\begin{abstract}
RESUMO
No processo de extração do óleo de soja forma-se a Micela, que é uma mistura de óleo e hexano. O processo de separação destes dois componentes é denominado de Destilação da Micela. Esta é composta basicamente da operação de evaporação e da operação de stripping do hexano. Neste trabalho, desenvolveu-se uma modelagem matemática para a evaporação do hexano. O modelo é baseado em balanços de massa e energia e em relações de equilibrio; e a sua validação foi feita comparando-se os resultados obtidos com os dados operacionais da indústria da COAMO (Cooperativa Agrícola Mouraoense). Em seguida, com o modelo elaborado, fez-se as simulações para estudar: as influências da temperatura do fluido de aquecimento e da vazão de alimentação na concentração de saída do evaporador; os efeitos da temperatura da alimentação, da concentração e da pressão nos resultados operacionais dos evaporadores; e a comparação entre resultados considerando a micela como solução real e ideal.

Palavras-chave: modelagem; simulação; micela e evaporação.
\end{abstract}

\section{SUMMARY}

DESTILATION OF THE MICELLA I: MODELING AND SIMULATION OF THE HEXAN EVAPORATION. In the soybean oil extraction process make the Micella that is a mixture of oil and hexane. The separation process in both components is named Micella Distillation. It is composed mainly of the hexane evaporation and of the hexane stripping. In this work, it was developed a mathematical modeling of the hexane evaporation. This model is based in mass and energy balances and in equilibrium relations. The validity of the model was made comparing the obtained results with data from a industry of the COAMO (Cooperativa Agricola Mouraoense). In following, with the elaborated model, it was made the simulation of the evaporation to study: the influences of the temperature of the heating fluid and of the feed flow in the outlet evaporator concentration; the effects of the feed temperature, concentration and pressure over operation results of the evaporators; and, the comparison between the results considering the micella as real and ideal solution.

Keywords: modeling; simulation; micella and evaporation.

\section{1 - INTRODUÇÃO}

A industrialização de oleaginosas constitui-se num dos mais importantes setores do sistema agroindustrial, pela importância de seus produtos nas indústrias siderúrgicas, de cosméticos e como matéria-prima no processamento de alimentos para o consumo animal e humano [1]. Ainda segundo este autor, a soja respondeu por $94,2 \%$ da produção e por $90,8 \%$ do consumo de óleos vegetais no Brasil em 1995/1996, sendo, portanto, a mais importante matéria-prima da cadeia de produção de óleos vegetais. Além disso, o Brasil se destacou no período 1997/1998 no comércio internacional do complexo soja, por liderar as exportações mundiais de farelo, em torno de $30 \%$ do volume comercializado no mundo, bem como a segunda colocação nas exportações mundiais de óleo de soja com aproximadamente $21 \%$ do total. De tal forma que o complexo soja gerou em divisas para o país, em 1997, o valor em torno de US\$ 5,5 bilhões incluindo, neste caso, grãos, óleo e farelo.

Uma estratégia importante visando a redução de custos e a proteção do meio ambiente e do consumidor, nas indústrias já instaladas, é procurar estabelecer as melhores condições de operação do processo. Tais con-

\footnotetext{
1. Recebido para publicação em 23/07/2002. Aceito para publicação em 28/04/2003 (000902).

22Departamento de Engenharia Química,UEM-Maringá, paulo@deq.uem.br, cid@deq.uem.br

${ }^{3}$ Departamento de Sistemas Quimicos - FEQ/UNICAMP-Campinas, zemp@desq.feq.unicamp.br

* A quem a correspondência deve ser enviada.
}

dições podem propiciar um consumo menor de energia e um nivel mais elevado de recuperação de hexano. As indústrias instaladas no Paraná/Brasil utilizam o processo contínuo de extração por solvente, sendo hexano o solvente utilizado. As operações deste processo que deverão ser principais numa estratégia de redução de custos são: a extração do óleo por solvente, a destilação da micela e a dessolventização-tostagem do farelo uma vez que elas consomem muita energia e possuem uma intensa manipulação com o hexano, [11].

A micela é uma mistura entre óleo de soja e o hexano formada no extrator. A separação destes componentes é denominada de Destilação da Micela, que se compõe: da evaporação e do 'stripping' do hexano. Nestas operações, quantidades expressivas de energia são utilizadas, na forma de vapor. O valor estimado por JONGENEELEN [9] é de 40kg de vapor por tonelada de soja processada.

Este trabalho apresenta a modelagem matemática e simulação da etapa de evaporação do hexano. A validação do modelo desenvolvido será feita através da comparação dos dados gerados com os dados operacionais da indústria da COAMO (Cooperativa Agrícola Mouraoense). $\mathrm{Na}$ seqüência, um conjunto de simulações serão executadas a fim de estudar: as influências da temperatura do fluido de aquecimento e da vazão de alimentação na concentração de saída do evaporador; os efeitos da temperatura da alimentação, da concentração e da pressão nos resultados operacionais dos evaporadores; e, a comparação entre resultados considerando a micela como solução real e ideal. 


\section{2 - MATERIAL E MÉTODOS}

\section{1 - O evaporador}

A evaporação na indústria de obtenção de óleo de soja é normalmente usada para evaporar o hexano puro e concentrar a micela. Os equipamentos normalmente utilizados são evaporadores verticais de tubos longos, instalados em série, que utilizam vapores saturados como fontes de calor para o aquecimento da micela até seu ponto de ebulição. Numa indústria típica, parte deste aquecimento é feito aproveitando os vapores saturados que saem da operação de dessolventização/ tostagem do farelo de soja e a outra parte é feita utilizando-se o vapor d'água saturado proveniente do sistema de utilidades. O evaporador utilizado na indústria para a evaporação da micela é semelhante ao mostrado na Figura 1.

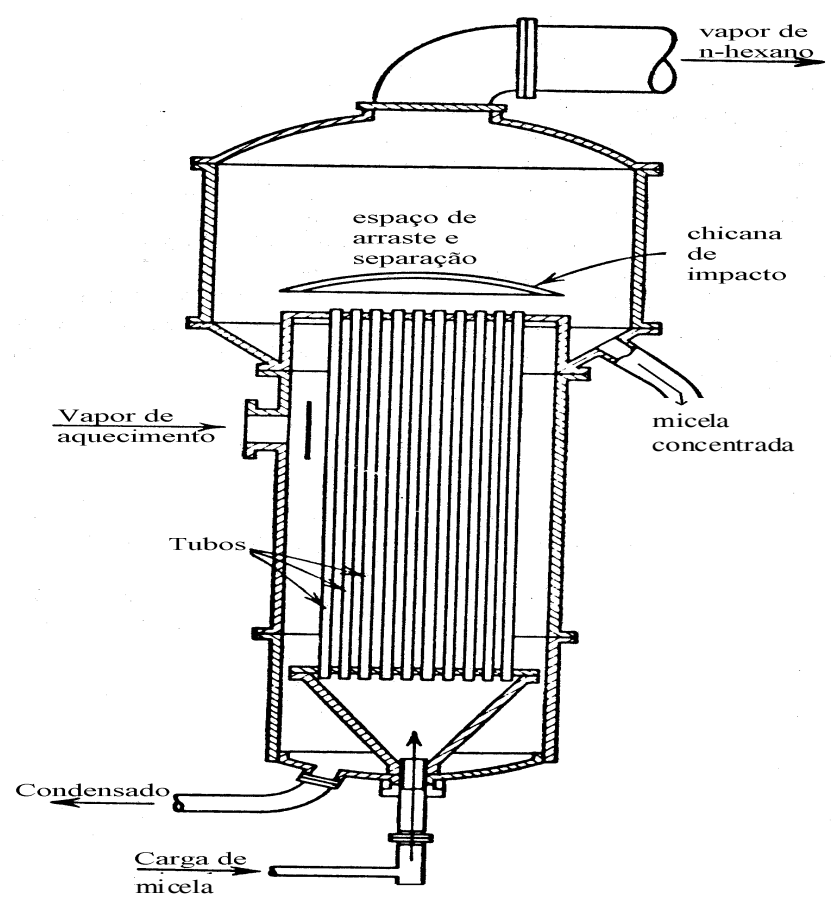

FIGURA 1. Evaporador típico da micela

Esse evaporador basicamente exerce a função de um trocador de calor, no qual o vapor de aquecimento flui na parte externa dos tubos e a micela escoa na parte interna dos tubos. A sua operação é de forma contínua e à medida que a micela vai subindo nos tubos esta se aquece até seu ponto de ebulição vaporizando grandes quantidades de hexano. Entretanto, o hexano é retirado do óleo até um certo valor limite de concentração, a partir do qual a temperatura de ebulição aumenta significativamente e se torna bastante dispendioso continuar retirando todo hexano da micela. Além disso, uma temperatura de operação muito elevada pode alterar as características fisicas do óleo de soja, tornando-o impróprio para o consumo[15].

\section{2 - $O$ modelo matemático do evaporador}

A Figura 2 mostra esquema geral do evaporador onde a micela recebe calor de um de fluido de aquecimento; ao receber este calor, a solução entra em ebulição vaporizando o hexano e se concentrando.

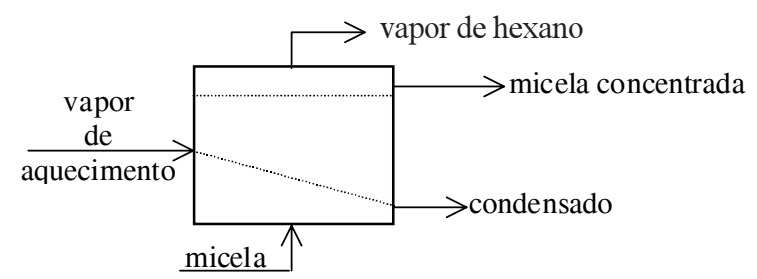

FIGURA 2. Esquema das correntes de entrada e saída do evaporador

A seguir, será apresentado um modelo para prever o comportamento de um evaporador em condições diversas. Porém, estas não são muito distantes dos pontos normais de operação pelas próprias características do modelo matemático gerado. É importante ressaltar que a literatura sobre modelagem de evaporação é relativamente extensa. Existe um grande número de textos sobre o tema, principalmente para a sintese. $\mathrm{Na}$ análise destacam-se o trabalho de HOLLAND [8], de CHIAPETTA et al.[3] e de HELDMAN \& LUND [6]. Nesses trabalhos, os modelos no que se referem aos balanços de massa e de energia são semelhantes, o que os diferem é a forma de estimar a temperatura de equilíbrio na ebulição. Para tanto, HOLLAND [8] sugere a utilização de dados experimentais de equilibrio apresentados na forma de gráficos de Duhring, os quais podem ser vistos em MCCABE et al. [10] para algumas soluções, tais como a de $\mathrm{NaCl}$ ou $\mathrm{NaOH}$; Chiapetta utiliza equações empíricas na modelagem da evaporação do caldo-de-cana; já HELDMAN \& LUND [6] usam os principios que envolvem o equilibrio termodinâmico para prever essa temperatura, embora considerando que os efeitos provenientes da interação entre os componentes da mistura sejam despreziveis. Neste trabalho, estas interações serão consideradas e o coeficiente de atividade do hexano será previsto através do UNIFAC.

A modelagem utilizada neste trabalho está relacionada a evaporadores de efeito simples operando em regime permanente. As relações matemáticas do modelo são resultantes dos balanços materiais e térmicos, dos dados de transmissão de calor e das relações de equilibrio. Além disso, as seguintes hipóteses serão consideradas: I) as contribuições dos outros processos de transferência têm pequena importância sobre o processo, que é completamente controlado pelas taxas de transferência de calor; II) a temperatura e a pressão total da fase vapor são consideradas iguais à temperatura e à pressão total da fase liquida desprezando, portanto, o efeito da pressão hidrostática; III) o solvente denominado de hexano é composto apenas do hidrocarboneto n-hexano; IV) o vapor do hexano que sai do evaporador é puro, na temperatura da solução e na pressão de operação do evaporador; V) as perdas de calor do sistema para as 
vizinhanças são consideradas nulas; e, VI) as variações das energias cinética e potencial são despreziveis.

A Figura 3 mostra as correntes e especificações de entrada e de saída do evaporador.

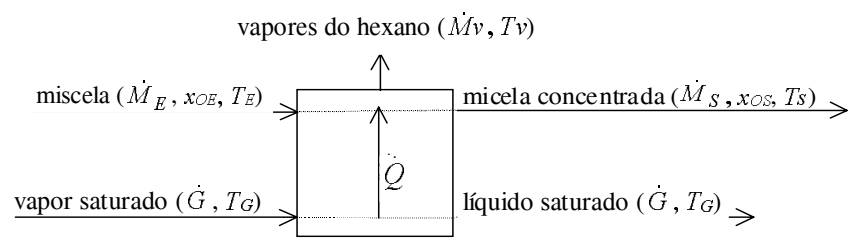

FIGURA 3. Correntes que entram e saem do evaporador e suas especificações

Sendo $\dot{M}_{E}$ a vazão molar da micela que entra no evaporador (moles $/ \mathrm{h}$ ); $x_{O E}$ a fração molar do óleo que entra no evaporador (moles de óleo/moles de micela); $T_{E}$ a temperatura da micela que entra no evaporador $\left({ }^{\circ} \mathrm{C}\right) ; \dot{G}$ a vazão molar do fluido de aquecimento que entra e sai do evaporador (moles/h); $T_{G}$ a temperatura do fluido de aquecimento na entrada do evaporador $\left({ }^{\circ} \mathrm{C}\right) ; \dot{M}_{S}$ a vazão molar da micela que sai do evaporador (moles $/ \mathrm{h}$ ); $x_{O S}$ a fração molar do óleo que sai do evaporador (moles de óleo/moles de micela); Ts a temperatura da micela na saída do evaporador $\left({ }^{\circ} \mathrm{C}\right) ; \dot{M} v$ a vazão molar do hexano que sai do evaporador (moles/h); Tv a temperatura do vapor de hexano que sai do evaporador $\left({ }^{\circ} \mathrm{C}\right)$; e $\dot{Q}$ o calor trocado através da superficie de transferência (kcal/h).

Os balanços materiais para os fluxos de hexano e de óleo são os seguintes:

Balanço de massa global:

$\dot{M}_{E}=\dot{M}_{S}+\dot{M}_{V}$

Balanço de massa para o óleo:

$\dot{M}_{E} x_{O E}=\dot{M}_{S} x_{O S}$

e

$x_{O}+x_{h}=1$

sendo $\mathrm{x}_{\mathrm{O}}$ e $\mathrm{x}_{\mathrm{h}}$ as frações molares do óleo e o hexano em qualquer ponto do sistema de evaporação.

O balanço de energia deverá relacionar a variação da entalpia no lado da solução à do fluido aquecedor. Assim, desprezando-se as perdas de calor, a equação do balanço de energia será a seguinte:

$$
\dot{M}_{E} H_{E}+\dot{Q}=\dot{M}_{S} H_{S}+\dot{M}_{V} H_{S}
$$

sendo $H_{E}$ e $H s$ as entalpias da micela na entrada e na saída do evaporador e $H v$ a entalpia do vapor do hexano. Estas podem ser calculadas através das seguintes expressões:

$H_{E}=x_{O E} c_{p o}\left(T_{E}-T_{r}\right)+\left(1-x_{O E}\right) c_{p h}\left(T_{E}-T_{r}\right)$

sendo $T_{r}$ a temperatura de referência, $c_{p o}$ a capacidade calorífica do óleo de soja e $c_{p h}$ e do hexano no estado liquido.

O calor liberado pelo fluido de aquecimento é dado pela seguinte equação

$$
\dot{Q}=\dot{G} \lambda
$$

sendo $\lambda$ é o calor latente de vaporização do fluido de aquecimento e a quantidade condensada deste fluido

A entalpia da solução na saída do evaporador é dada por:

$H_{S}=x_{O S} c_{p o}\left(T_{S}-T_{r}\right)+\left(1-x_{O S}\right) c_{p h}\left(T_{S}-T_{r}\right)$

A entalpia do vapor de hexano que sai do evaporador é dada por:

$H_{V}=\Delta H_{V}^{W}+c_{p h y}\left(T_{v}-T_{W}\right)$

sendo $\Delta H_{V}{ }^{W}$ a entalpia de vaporização do hexano puro na pressão do sistema e $c_{p h y}$ a capacidade calorífica do hexano no estado de vapor.

Uma vez que, neste trabalho, está-se supondo que as temperaturas $T s$ e $T v$ são iguais, ou seja, $T s=T v=T$ as equações (7) e (8) ficam da seguinte forma:

$H s=x_{O S} c_{p o}\left(T-T_{r}\right)+\left(1-x_{O S}\right) c_{p h}\left(T-T_{r}\right)$

e

$H_{V}=\Delta H_{V}{ }^{W}+c_{p h y}\left(T-T_{W}\right)$

sendo $T$ a temperatura de ebulição da solução na pressão $P$ do evaporador. Como foi visto, esta temperatura depende da concentração da solução e da pressão de operação do evaporador; ela pode ser determinada de várias maneiras, embora a mais exata seja a experimental, HELDMAN \& LUND [6]. Quando os dados experimentais não estão disponiveis pode-se utilizar o método estimativo baseado nos princípios do equilibrio termodinâmico.

Diversos autores, tais como CASTELLAN [2] e SANDLER [14] apresentam modelos que descrevem 
esse equilibrio que culmina na relação entre a temperatura de ebulição da solução, $T$, e a concentração do solvente $x_{h}$. Neste trabalho, será utilizado o modelo apresentado por SANDLER [14] por considerá-lo mais abrangente, que é o seguinte:

$$
\ln \left(\gamma_{h} x_{h}\right)=\frac{\Delta H_{v}{ }^{w}}{R}\left(\frac{1}{T}-\frac{1}{T_{w}}\right)+\frac{c_{p_{h}}}{R}\left[1-\frac{T_{w}}{T}+\ln \left(\frac{T_{w}}{T}\right)\right]
$$

sendo $\gamma_{h}$ o coeficiente de atividade do hexano presente na micela, $\Delta H_{v}{ }^{w}$ o calor de vaporização do hexano puro na temperatura de saturação, $T_{W}$, e na pressão, $P$ do sistema, $c_{p h}$ a capacidade calorifica do hexano e $R$ a constante universal dos gases. O valor de $T_{W}$ pode ser estimado através da equação de Antoine [7]. Esta equação é a seguinte:

$T_{W}=\frac{2697,55}{15,8366-\ln P}-224,52$

sendo $T_{W}$ expressa em ${ }^{\circ} \mathrm{C}$ e $P$ expressa em $\mathrm{mmHg}$.

O fluxo de calor através dos tubos de área, $A$, é calculado da seguinte maneira:

$\dot{Q}=U A \Delta T$

sendo $\dot{Q}$ a taxa de calor transferida; U o coeficiente global de transferência de calor; e $\Delta T$ a diferença de temperatura entre o fluido e a solução.

\section{3 - Simulação da evaporação da micela}

\subsection{1 - Desenvolvimento do algoritmo}

Aqui pretende-se apresentar um procedimento para analisar o desempenho da operação de evaporação da micela. A meta principal é a obtenção da concentração do óleo que pode ser alcançadas a partir das seguintes especificações: $\dot{M}_{E}, x_{O E}, T_{E}, U$ e $A$.

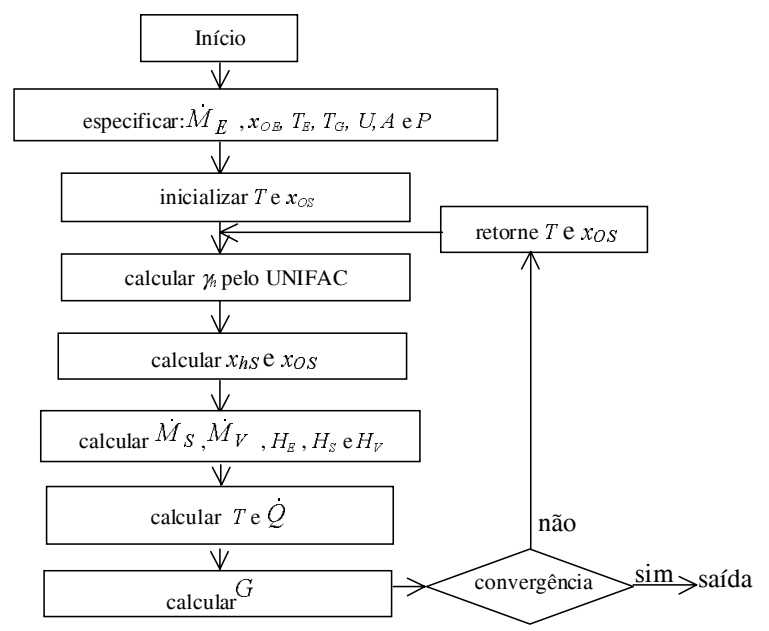

FIGURA 4. Algoritmo para simular a evaporação da micela
Como $\dot{M}_{S}$ e $\mathrm{x}_{\mathrm{OS}}$ são incógnitas, o valor de $\mathrm{x}_{\mathrm{OS}}$ pode ser determinado a partir da equação (11) em conjunto com as equações (3) e (2). Ocorre que a temperatura da solução, T, também é desconhecida, logo um processo iterativo é necessário para resolver o problema, da seguinte forma: I) inicializar a temperatura e a fração molar da solução; II) calcular o coeficiente de atividade pelo UNIFAC; III) calcular as concentrações na saída através das equações (11) e (3); IV) fazer o balanço de massa para obter as vazões pelas equações (1) e (2); V) fazer o balanço térmico para determinar o fluxo de calor através da equação (4) em conjunto com as equações (5), (9) e (10); VI) a temperatura da solução, $T$, é calculada a partir do fluxo de calor pela equação (13); VII) calcular o consumo de vapor, $\dot{G}$, através da equação (6); e, VIII) se necessário, fazer a iteração, conforme mostra a Figura 4.

O esquema da Figura 4 mostra as etapas gerais para o cálculo de diversas variáveis que irão possibilitar a análise operacional do evaporador. Para os cálculos, um programa computacional em linguagem FORTRAN foi estruturado como a seguir:

O programa inicia com a leitura dos dados de entrada que são: a pressão de operação do sistema, $P$ em $\mathrm{mmHg}$; a vazão molar da micela que entra no evaporador, $\dot{M}_{E}$ em moles/h; a fração molar do óleo na entrada do evaporador, $x_{O E}$; a temperatura da micela na entrada do evaporador, $T_{E}$ em ${ }^{\circ} \mathrm{C}$; a temperatura do fluido de aquecimento no evaporador, $T_{G}$ em ${ }^{\circ} \mathrm{C}$; a área de troca térmica do evaporador, $A$ em m $\mathrm{m}^{2}$; e, o coeficiente global de transferência de calor, $U$ em $\mathrm{kcal} / \mathrm{hm}^{2}{ }^{\circ} \mathrm{C}$.

Após a entrada de dados o programa realiza uma série de cálculos, cujo objetivo é a determinação do grau de separação do hexano do óleo de soja no evaporador. O processo de cálculo, se inicia com a suposição de um valor inicial para a temperatura de ebulição, $T$, e para a concentração da micela, que possibilitam o cálculo do coeficiente de atividade do hexano, $\gamma_{h}$ através do UNIFAC. A partir $\gamma_{h}$, Te $P$, o programa realiza o cálculo da concentração molar do hexano na micela na saída do evaporador. Com este valor determinado, faz-se os balanços de massa e energia e o processo iterativo se for necessário. A convergência do valor de $T$ no processo iterativo apresentado no algoritmo da Figura 4 é efetuado, no programa, pela sub-rotina CONV. Esta sub-rotina é baseada no método de convergência algébrica de Wegstein, em FRANKS [5], e tem a função de, quando chamada, comparar o valor de $T$ inicialmente suposto com o valor calculado no programa principal. Se a diferença entre os dois valores for maior do que 0,0001 considera-se que a convergência não foi alcançada e o valor de $T$ calculado retorna ao início do processo de cálculos para se obter um novo valor de $T$ e o processo se repete até atingir a diferença desejada entre valor anterior e o novo valor calculado de $T$. Caso a diferença entre os dois valores de $T$ seja menor do que 0,0001, considera-se que a convergência foi atingida e este valor de $T$ é o verdadeiro valor para a temperatura de saída da solução. Além disso, para cada par de valores composto pela temperatura e concentração molar da micela determinados, o programa 
determina um novo valor para coeficiente de atividade do hexano, que participará do cálculo da concentração da micela. Encerrado o processo iterativo, o programa principal emite os resultados obtidos.

A saída de resultados compõe-se dos seguintes dados: concentração do óleo, $x_{O S}$; e temperatura da solução, $T$, saída do evaporador; o consumo do fluido de aquecimento, e, as vazões do hexano e da micela na saída do evaporador, $\dot{M}_{v}$ e $\dot{M}_{S}$.

\subsection{2 - Dados operacionais dos evaporadores}

A evaporação de solvente da indústria de óleo da COAMO opera com dois evaporadores, em série, denominados respectivamente de primeiro evaporador e de segundo evaporador, cuja característica que os diferenciam é a área de troca térmica; o primeiro tem $315 \mathrm{~m}^{2}$ de e segundo tem $95 \mathrm{~m}^{2}$. Ambos operam a uma pressão de $300 \mathrm{~mm} \mathrm{Hg}$. A micela com uma concentração em torno de $26 \%$ em óleo entra no primeiro evaporador a uma temperatura de $49^{\circ} \mathrm{C}$ e recebe calor dos vapores de hexano/água provenientes do dessolventizador-tostador de farelo, os quais entram no evaporador a uma temperatura de $71^{\circ} \mathrm{C}$; com isso o hexano evapora-se indo, em seguida, para o condensador e a micela concentrada em torno de $65 \%$,em massa, de óleo sai a uma temperatura em torno de $50^{\circ} \mathrm{C}$. Em seguida, essa micela vai ao segundo evaporador e, antes de entrar neste, é pré-aquecida uma temperatura de aproximadamente $59^{\circ} \mathrm{C}$. Nesse evaporador, a micela recebe mais calor da condensação do vapor d'água saturado a $127^{\circ} \mathrm{C}$; com isso mais uma quantidade de hexano é evaporada e a micela atinge uma concentração mássica em óleo em torno de $98 \%$.

Um dos parâmetros de grande importância na análise dos evaporadores é o coeficiente global de transferência de calor, $U$. Neste trabalho, as estimativas dos valores de $U$ para os dois evaporadores são conforme os dados apresentados por PERRY \& CHILTON [13]. Estes autores mostram que o coeficiente global de transferência de calor, para evaporadores verticais de tubos longos, aumenta com o aumento da temperatura para fluidos considerados viscosos; além disso, a viscosidade da micela diminui com o aumento da temperatura e esta tendência de queda da viscosidade é mais acentuada nas concentrações mais elevadas em termos de óleo [12].

Além da observação já mencionada, PERRY \& CHILTON [13] mostram valores de U em gráficos e tabelas considerando o tipo de evaporador, as faixas de temperatura de operação e, em alguns casos, os tipos de materiais que atuam no processo: como fluido quente e como fluido frio. Levando em consideração, os dados apresentados por estes autores e as características do processo, como tipo de evaporador, faixas de temperatura e materiais envolvidos estimou-se os valores do coeficiente global de transferência de calor. O valor estimado de $\mathrm{U}$ é igual a $171 \mathrm{kcal} / \mathrm{hm}^{2 \circ} \mathrm{C}$ para o primeiro evaporador que opera numa temperatura em torno de $50^{\circ} \mathrm{C}$ e igual a $977 \mathrm{kcal} / \mathrm{hm}^{2}{ }^{\circ} \mathrm{C}$ para o segundo evaporador que opera numa temperatura em torno de $120^{\circ} \mathrm{C}$. Observa-se que o valor de U é influenciado pela temperatura do evaporador, que por sua vez influencia a viscosidade, principalmente nas faixas de concentrações de óleo mais elevadas.

Além do coeficiente global de transferência de calor, o calor latente dos fluidos quentes ou dos seus componentes devem ser estimados. Para o primeiro evaporador, o calor latente liberado é formado por duas parcelas: uma é condensação de parte do hexano e a outra formada é condensação de parte do vapor d'água. O valor do calor latente do hexano nas condições que ele sai da operação de dessolventização/tostagem do farelo pode ser considerado como $80 \mathrm{kcal} / \mathrm{kg}$ e o calor latente da água como $540 \mathrm{kcal} / \mathrm{kg}$; ponderando estes valores em relação às quantidades de cada um dos componentes, chega-se a um valor estimado para o calor latente da mistura condensada na ordem de $124 \mathrm{kcal} /$ $\mathrm{kg}$. Para o segundo evaporador, o fluido utilizado é vapor d'água saturado à temperatura de $127^{\circ} \mathrm{C}$, assim o calor latente é de $521 \mathrm{kcal} / \mathrm{kg}$.

A Tabela 1 apresenta um resumo dos dados operacionais obtidos da indústria de obtenção de óleo de soja da COAMO. Estes serão aplicados ao modelo e, também, serão utilizados na comparação dos resultados obtidos nas simulações.

TABELA 1. Dados Operacionais da COAMO

\begin{tabular}{lccc}
\hline \multicolumn{4}{c}{ Dados operacionais } \\
\hline \multicolumn{1}{c}{ discriminação } & símbolo & $1^{\circ}$ evaporador & $2^{\circ}$ evaporador \\
\hline vazão mássica da micela na entrada & $m_{R}$ & $28240 \mathrm{kghh}$ & $11290 \mathrm{~kg} / \mathrm{h}$ \\
vazão mássica da micela na saída & $m_{S}$ & $11290 \mathrm{kghh}$ & $7490 \mathrm{kghh}$ \\
vazão mássica do hexano na saída & $m_{V}$ & 16950,0 & 3800,0 \\
fração mássica do óleo na entrada & $X_{O R}$ & $26 \%$ & $65 \%$ \\
fração mássica do óleo na saída & $X_{O S}$ & $65 \%$ & $98 \%$ \\
temperatura da micela na entrada & $T_{I}$ & $49^{\circ} \mathrm{C}$ & $59^{\circ} \mathrm{C}$ \\
temperatura da micela na saída & $T$ & $50^{\circ} \mathrm{C}$ & $119,8^{\circ} \mathrm{C}$ \\
temperatura do fluido de aquecimento & $T_{G}$ & $71^{\circ} \mathrm{C}$ & $127^{\circ} \mathrm{C}$ \\
pressão de operação & $P$ & $300 \mathrm{mmHg}$ & $300 \mathrm{mmHg}$ \\
área de troca térmica & $A$ & $315 \mathrm{~m} \mathrm{~m}^{2}$ & $95 \mathrm{~m}^{2}$ \\
vazão vapor do DT na entrada do evaporador & $G_{I}$ & $12083 \mathrm{kghh}$ & - \\
\hline
\end{tabular}

Os dados de vazão e de concentração presentes na Tabela 1 coletados na COAMO estão expressos em unidades de massa. Para transformá-los em unidades molares utiliza-se o peso molecular do hexano puro, que é igual a $86,17 \mathrm{~g} / \mathrm{mol}$ e o peso molecular médio do óleo igual a $265,2 \mathrm{~g} / \mathrm{mol}[12]$.

\section{3 - RESULTADOS E DISCUSSÃO}

As simulações efetuadas possibilitam apresentar os resultados, para discussão, em duas etapas. Em primeiro lugar, a comparação entre os valores das variáveis de chegada (temperatura e concentração) obtidos através do modelo e aqueles coletados na indústria da cooperativa COAMO. Na seqüência, a apresentação e discussão de resultados sobre o comportamento de determinadas variáveis, provenientes de alterações impostas às condições de operação do processo em estudo.

\section{1 - Comparação entre os resultados do modelo e os operacionais}

A Tabela 2 apresenta os resultados obtidos da fração mássica do óleo na micela, da temperatura das cor- 
rentes na saida dos evaporadores, bem como os consumos do fluido de aquecimento nos dois evaporadores. Além disso, os valores das vazões da micela e do vapor de hexano que saem dos evaporadores.

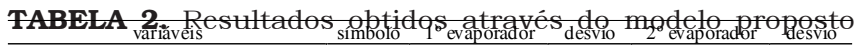
\begin{tabular}{lccccc}
\hline Fração mássica do óleo na saída & $X_{O S}$ & $64,1 \%$ & $1,4 \%$ & $98,8 \%$ & $0,8 \%$ \\
Temperatura da micela na sáda & $T$ & $50,1^{\circ} \mathrm{C}$ & $0,2 \%$ & $119,4^{\circ} \mathrm{C}$ & $0,3 \%$ \\
Vazão da micela na saída & $m_{S}$ & $11459,4 \mathrm{~kg} / \mathrm{h}$ & $1,5 \%$ & $7424,6 \mathrm{kgh}$ & $0,9 \%$ \\
Vazão do hexano na saída & $m_{V}$ & $16780,6 \mathrm{kgh}$ & $1,0 \%$ & $3865,4 \mathrm{~kg} / \mathrm{h}$ & $1,7 \%$ \\
Consumo de vapor & $\dot{\mathfrak{I}}$ & $10428,8 \mathrm{~kg} / \mathrm{h}$ & - & $1357,3 \mathrm{kgh}$ & - \\
\hline
\end{tabular}

Os resultados mostrados na Tabela 2 foram obtidos através do modelo desenvolvido após a inserção dos dados de entrada conforme especificado no algoritmo da Figura 4. A comparação destes resultados com os dados da Tabela 1 permite observar alguns aspectos importantes. O primeiro é que os resultados das concentrações da micela em óleo obtidos pelo modelo são próximos dos dados operacionais, sendo que a concentração em massa do óleo foi 1,4\% menor no primeiro evaporador e 0,8\% maior no segundo evaporador. O segundo aspecto se refere ao fato de que a recuperação do hexano foi 1,0\% menor no primeiro evaporador e de $1,7 \%$ superior no segundo evaporador. O terceiro aspecto diz respeito ao fato de que a temperatura da micela obtida a partir do modelo tem um valor de apenas $0,2 \%$ superior ao real no primeiro evaporador e, no segundo evaporador, o valor da temperatura simulada foi de apenas $0,3 \%$ inferior ao valor real; assim, a qualidade do óleo será mantida. Finalmente, os dados simulados mostram que o primeiro evaporador condensou $10428,8 \mathrm{~kg} / \mathrm{h}$ dos vapores da operação de dessolventização/tostagem do farelo e a parte não condensada de $1654,2 \mathrm{~kg} / \mathrm{h}$ foi enviada para os condensadores; no segundo evaporador, o vapor consumido é de $34 \mathrm{~kg} /$ tonelada de soja processada, valor coerente [11].

Como pode-se observar, as comparações entre os dados apresentados nas Tabelas 1 e 2 mostram que, apesar de pequenas, diferenças ocorreram entre as concentrações, as quantidades de hexano recuperadas e as temperaturas de ebulição. Isto pode ter ocorrido pelos seguintes motivos: erros inerentes aos dados experimentais; erros na estimativa de parâmetros; além daqueles provenientes das hipóteses do modelo, como as desconsiderações das perdas de calor do equipamento para o meio ambiente, da carga hidrostática e do calor de solução.

A seguir, apresentar-se-ão simulações a fim de verificar o efeito que determinadas alterações em variáveis 3rovocam no processo de evaporação.

\section{2 - Influência da temperatura do vapor de aque- cimento na concentração de saída do evaporador}

Mantendo-se fixos o valores de $\dot{M}_{E}, x_{O E}, T_{E}, U, A$ e $P$, incrementos sucessivos foram aplicados na temperatura do vapor de aquecimento, $T_{G}$. Com isto, foi possivel observar o comportamento da concentração mássica de saída do óleo na micela com a temperatura do fluido. Os resultados obtidos estão na Figura 5.

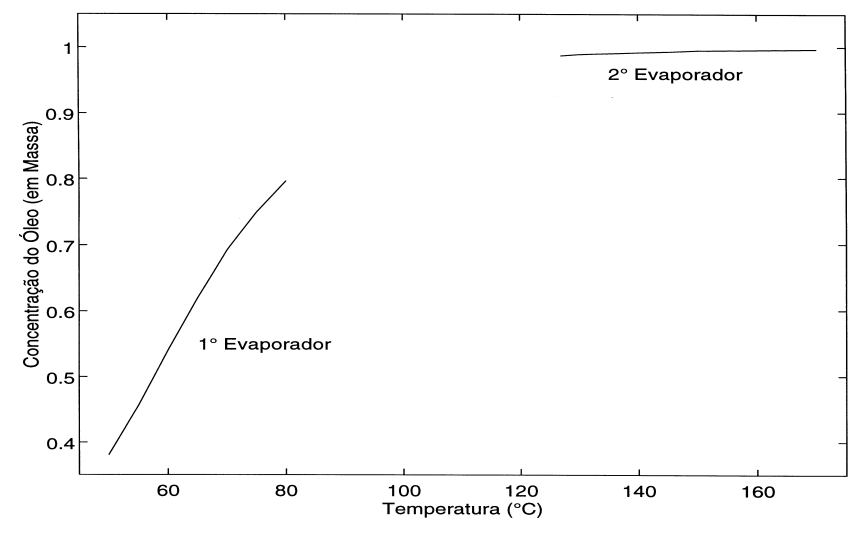

FIGURA 5. Influência da temperatura do vapor de aquecimento na concentração de saída

O gráfico da Figura 5 mostra que a concentração de saída aumenta com a temperatura, porém pode-se observar que é atingido um valor assintótico à medida que a solução se concentra. Esta característica mostra que existe um certo valor da concentração de saída a partir do qual não se recomenda aumentar o valor da temperatura a fim de aumentar essa mesma concentração. Ou seja, o caráter assintótico da curva, como já observou CHIAPPETA et al. [3], indica a existência de um ponto ótimo no que se refere ao consumo de energia no evaporador que, por sua vez, está relacionada à temperatura do fluido de aquecimento.

\section{3 - Influência da vazão de alimentação na con- centração de saída do evaporador}

Fixando-se $x_{O E}, T_{E}, T_{G}, U, A$ e $P$ e aplicando-se incrementos sucessivos na vazão de alimentação,. Assim, foi possivel verificar o efeito da vazão de alimentação da micela na concentração de saída do evaporador para uma temperatura especificada do fluido de aquecimento. Os resultados obtidos com o modelo estão na Figura 6.

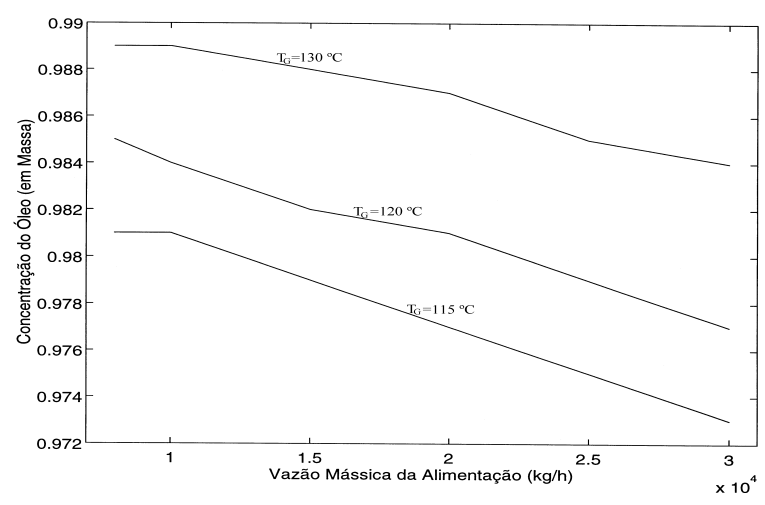

FIGURA 6. Influência da vazão de alimentação e da temperatura de vapor de aquecimento na concentração de saída do segundo evaporador 
A Figura 6 mostra uma diminuição nos valores da concentração de óleo à medida que se aumenta a vazão de alimentação; além disso, o gráfico também mostra os efeitos opostos na vazão de alimentação e na temperatura do fluido de aquecimento sobre a concentração da micela na saída do segundo evaporador. Assim, o controle dessas duas variáveis é fundamental para uma boa recuperação de solvente com economia de energia.

\section{4 - Efeito da temperatura da alimentação nos resultados operacionais dos evaporadores}

Este caso mostra as variáveis de saída dos evaporadores quando se implementa uma variação apenas na temperatura da alimentação de micela. Deve-se ressaltar que este estudo visa apenas constatar ou não possibilidades de integração energética do processo, sem se preocupar com a fonte de energia para o pré-aquecimento da micela. A Tabela 3 mostra os resultados obtidos com o modelo.

TABELA 3. Influência da temperatura de alimentação na operação dos evaporadores

\begin{tabular}{lccccccc}
\hline \multicolumn{7}{c}{ dados obtidos no primeiro evaporador } \\
\hline$T_{E}\left({ }^{\circ} \mathrm{C}\right)$ & 40 & 45 & 50 & 55 & 60 & 65 & 70 \\
$x_{O S}(\mathrm{em}$ massa) & 0,614 & 0,629 & 0,644 & 0,658 & 0.672 & 0,685 & 0,698 \\
$T\left({ }^{\circ} \mathrm{C}\right)$ & 48,84 & 49,50 & 50,19 & 50,90 & 51,68 & 52,37 & 53,13 \\
$\dot{G}(\mathrm{~kg} / \mathrm{h})$ & 11035,6 & 10702,5 & 10359,4 & 10007,0 & 9645,9 & 9276,4 & 8899,3 \\
\hline \multicolumn{7}{c}{ dados obtidos no segundo evaporador } \\
\hline$T_{E}\left({ }^{\circ} \mathrm{C}\right)$ & 45 & 50 & 55 & 60 & 65 & 70 & 75 \\
$x_{O S}(\mathrm{em}$ massa) & 0,988 & 0,988 & 0,988 & 0,988 & 0,989 & 0,989 & 0,989 \\
$T\left({ }^{\circ} \mathrm{C}\right)$ & 118,32 & 118,60 & 118,88 & 119,16 & 119,72 & 120,00 & 120,28 \\
$\dot{G}(\mathrm{~kg} / \mathrm{h})$ & 1546,5 & 1496,7 & 1446,9 & 1397,1 & 1297,6 & 1247,8 & 1198,0 \\
\hline
\end{tabular}

Como observa-se pela Tabela 3, o efeito do aumento de $T_{E}$ na alimentação se mostra mais significativo na redução do consumo de vapores do que na recuperação do solvente. No primeiro evaporador, para uma variação positiva de $30^{\circ} \mathrm{C}$, obteve-se apenas $13,7 \%$ de aumento na concentração da micela em termos de óleo. No entanto, os vapores da operação de dessolventização/tostagem do farelo reduziram a sua condensação em 24,0\%. Esta redução pode não ser benéfica, pois pode sobrecarregar os condensadores; a temperatura de saida sofreu uma pequena variação, em torno de $4^{\circ} \mathrm{C}$, a qual não altera a qualidade do óleo. No segundo evaporador, o aumento da temperatura de alimentação em $30^{\circ} \mathrm{C}$ praticamente não alterou o nivel concentração da micela em termos de óleo; a temperatura de saída aumentou por volta de $2{ }^{\circ} \mathrm{C}$, portanto não influencia na qualidade do óleo; no entanto, houve uma economia em vapor em torno de $30 \%$ nesse evaporador.

\section{5 - Efeito da concentração da alimentação nos resultados operacionais dos evaporadores}

A fim de verificar como se comporta o teor de recuperação do hexano, a temperatura da micela e o consumo de vapor quando ocorrem apenas variações na concentração da micela que alimenta o evaporador. Os dados foram aplicados ao modelo proposto e os resultados obtidos estão conforme a Tabela 4.

Os resultados apresentados na Tabela 4 mostram os efeitos das variações da concentração da alimenta- ção de micela nas saídas dos evaporadores. Em ambos evaporadores, o efeito mais significativo foi em relação à condensação dos vapores provenientes da dessolventização/tostagem no primeiro evaporador e o consumo de vapor d'água saturado no segundo evaporador; uma variação na concentração de alimentação de 50\% no primeiro evaporador promove uma redução na condensação dos vapores da dessolventização/ tostagem de apenas $16,3 \%$ e uma variação em torno de $40 \%$ na concentração da alimentação no segundo evaporador promove uma economia de vapor da ordem de 34\%. O efeito sobre a concentração de óleo na saída do evaporador e, portanto, na recuperação de hexano foi em torno de $12 \%$ no primeiro evaporador e praticamente insignificante no segundo evaporador. Nos dois casos houve uma ligeira elevação das temperaturas da micela, cujos valores não comprometem a qualidade do óleo.

TABELA 4. Influência da concentração de alimentação na operação do evaporador

\begin{tabular}{lcccccc}
\hline & \multicolumn{7}{c}{ primeiro evaporador } \\
\hline$x_{O E}(\mathrm{em}$ massa) & 0,20 & 0,22 & 0,24 & 0,26 & 0,28 & 0,30 \\
$x_{O S}(\mathrm{em}$ massa) & 0,596 & 0,612 & 0,627 & 0,641 & 0,654 & 0,667 \\
$T\left({ }^{\circ} \mathrm{C}\right)$ & 48,06 & 48,74 & 49,40 & 50,05 & 50,70 & 51,28 \\
$\dot{G}(\mathrm{~kg} / \mathrm{h})$ & 11420,8 & 11084,0 & 10753,7 & 10428,8 & 10108,9 & 9817,8 \\
\hline \multicolumn{7}{c}{ segundo evaporador } \\
\hline$x_{O E}(\mathrm{em}$ massa) & 0,54 & 0,58 & 0,62 & 0,66 & 0,70 & 0,75 \\
$x_{O S}(\mathrm{em}$ massa) & 0,988 & 0,988 & 0,988 & 0,988 & 0,989 & 0,989 \\
$T\left({ }^{\circ} \mathrm{C}\right)$ & 118,22 & 118,63 & 119,06 & 119,49 & 119,42 & 120,45 \\
$\dot{G}(\mathrm{~kg} / \mathrm{h})$ & 1564,6 & 1491,2 & 1414,7 & 1338,2 & 1261,7 & 1166,1 \\
\hline
\end{tabular}

Poder-se-ia também fazer a seguinte análise: partese com 0,2 e concentra-se até 0,596, utilizando-se $11420,0 \mathrm{~kg} / \mathrm{h}$ de vapor. Esta concentração de saída é próxima de 0,58 na entrada do segundo evaporador que concentra até 0,988 gastando $1491,2 \mathrm{~kg} / \mathrm{h}$ de vapor. Agora, parte-se do primeiro evaporador com uma concentração de 0,3 e concentro até 0,667gastando 9817,8 kg/h de vapor; esta concentração de saída é próxima de 0,66 na entrada do segundo evaporador que concentra até 0,998 utilizando $1338,2 \mathrm{~kg} / \mathrm{h}$ de vapor. Observa-se, portanto, que gastou-se na primeira situação $12912,0 \mathrm{~kg} / \mathrm{h}$ de vapor e na segunda11156,0 gerando uma economia de energia em torno de $16 \%$.

\section{6 - Efeito da pressão de operação nos resultados operacionais dos evaporadores}

Esta situação visa verificar o efeito de alterações na pressão de operação (vácuo) dos evaporadores provocam na concentração do óleo, na temperatura da solução e no consumo de vapor. A Tabela 5 mostra os resultados com o modelo proposto.

TABELA 5. Influência da pressão de operação (vácuo) na operação dos evaporadores

\begin{tabular}{lcccccccc}
\hline & \multicolumn{7}{c}{ primeiro evaporador } \\
\hline$P(\mathrm{mmHg})$ & 200 & 225 & 250 & 275 & 325 & 350 & 375 & 400 \\
$X_{\text {OS }}(\mathrm{em}$ massa $)$ & 0,784 & 0,763 & 0,714 & 0,680 & 0,606 & 0,572 & 0,539 & 0,510 \\
$T\left({ }^{\circ} \mathrm{C}\right)$ & 48,08 & 48,30 & 48,93 & 49,45 & 50,67 & 51,38 & 52,15 & 52,93 \\
$\dot{G}(\mathrm{kgh})$ & 11411 & 11304 & 10990 & 10731 & 10123 & 9768 & 9383 & 8998 \\
\hline \multicolumn{7}{c}{ segundo evaporador } \\
\hline$P(\mathrm{mmHg})$ & 200 & 225 & 250 & 275 & 325 & 350 & 375 & 400 \\
$X_{\text {oS }}(\mathrm{em}$ massa $)$ & 0,994 & 0,993 & 0,991 & 0,990 & 0,987 & 0,985 & 0,984 & 0,982 \\
$\left.T \dot{\circ}^{\circ} \mathrm{C}\right)$ & 119,3 & 119,4 & 119,4 & 119,4 & 119,4 & 119,4 & 119,4 & 119,4 \\
$\dot{G}(\mathrm{kgh})$ & 1364 & 1363 & 1360 & 1359 & 1356 & 1354 & 1352 & 1350 \\
\hline
\end{tabular}


A Tabela 5 mostra uma variação de $200 \mathrm{mmHg}$ na pressão dos evaporadores. Estas alterações significativas na pressão de operação (vácuo) provocam mudanças significativas nas variáveis analisadas apenas no primeiro evaporador onde a concentração do hexano ainda é elevada. No segundo evaporador onde o teor de hexano é baixo, as alterações na pressão provocam mudanças praticamente insignificantes na concentração do óleo da micela, na temperatura da solução e no consumo de vapor.

\section{7 - Comparação entre os resultados obtidos con- siderando a micela como solução real e ideal}

Este caso mostra a comparação entre os resultados obtidos na saída dos evaporadores quando se considera a solução da micela, a ser concentrada em óleo, como uma solução real, usando-se a atividade nos cálculos, e como uma solução ideal usando-se a concentração. A Tabela 6 mostra os resultados obtidos nos dois casos.

TABELA 6. Comparação entre os resultados de saída da micela como solução real e ideal

\begin{tabular}{|c|c|c|c|c|c|c|}
\hline \multicolumn{7}{|c|}{ Resultados obtidos } \\
\hline Evaporadores & \multicolumn{3}{|c|}{$1^{\circ}$ evaporador } & \multicolumn{3}{|c|}{$2^{\circ}$ evaporador } \\
\hline variáveis de saída & $\begin{array}{c}\text { simulado } \\
\text { real }\end{array}$ & $\begin{array}{c}\text { simulado } \\
\text { ideal }\end{array}$ & desvio & $\begin{array}{c}\text { simulado } \\
\text { real }\end{array}$ & $\begin{array}{c}\text { simulado } \\
\text { ideal }\end{array}$ & desvio \\
\hline fração mássica de óleo (\%) & 64,1 & 55,6 & $13,3 \%$ & 98,8 & 98,7 & $0,1 \%$ \\
\hline temperatura da micela $\left({ }^{\circ} \mathrm{C}\right)$ & 50,1 & 51,8 & $1,4 \%$ & 119,4 & 119,4 & $0,0 \%$ \\
\hline vazão da micela $(\mathrm{kg} / \mathrm{h})$ & 11459 & 13215 & $15,3 \%$ & 7424 & 7446 & $0,3 \%$ \\
\hline vazão do hexano $(\mathrm{kg} / \mathrm{h})$ & 16781 & 15025 & $10,5 \%$ & 3865 & 3843 & $0,6 \%$ \\
\hline consumo de vapor $(\mathrm{kg} / \mathrm{h})$ & 10429 & 9573 & $8,2 \%$ & 1357 & 1353 & $0,3 \%$ \\
\hline
\end{tabular}

A comparação entre os resultados simulados, para a solução real e ideal, da Tabela 6 possibilita verificar uma significativa alteração nos valores das variáveis de saída no primeiro evaporador, principalmente, no que se refere à concentração de saída da micela, à vazão de micela, à vazão de hexano e o consumo de vapor. Isto pode ser observado através dos desvios apresentados, com exceção da temperatura de saída que apresenta resultados muito próximos. No entanto, para o segundo evaporador não se observam diferenças nos resultados quando se considera uma solução real e uma solução ideal. Isto pode ser explicado pelo fato de que a concentração de saída está próxima de 1 e a atividade e a concentração serem praticamente iguais, como mostra a Figura 7. Especificamente, pode-se observar que a diferença nos valores da concentração do óleo na micela foi bem superior no primeiro evaporador relativamente ao segundo evaporador. Essa diferença está coerente uma vez que a tendência de evaporação é mais acentuada, em situações onde as concentrações do hexano na solução são mais elevadas.

A curva da Figura 7 mostra o desvio da idealidade do hexano na solução formada com o óleo de soja. Essa mostra a curva na diagonal representando a condição considerada ideal de equilíbrio e a outra representa a condição real de equilíbrio, entre o hexano e o óleo de soja. Esta configuração é fundamental na escolha da operação que deverá separar o restante do hexano presente no óleo, conforme CUSACK [4].

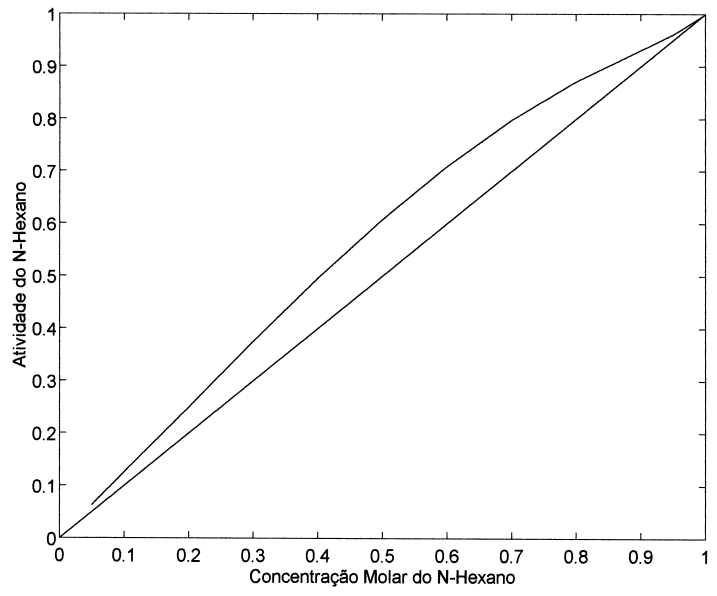

FIGURA 7. Desvio da idealidade da solução de óleo de soja/ hexano

\section{4 - CONCLUSÕES}

- O objetivo do trabalho foi apresentar um modelo capaz de analisar as condições de operação dos evaporadores na tarefa de separar o óleo de soja do hexano.

- Os resultados obtidos mostraram que o modelo proposto é bastante coerente e pode ser perfeitamente utilizado como ferramenta no processo de análise e otimização da operação de evaporação do hexano presente na micela.

- O modelo mostrou, através das simulações, que é possivel encontrar o ponto onde se deve operar os evaporadores, para se ter uma recuperação máxima de hexano com o consumo mínimo de energia.

\section{5 - REFERÊNCIAS BIBLIOGRÁFICAS}

[1] BARBosA, M. Z., de FREITAS, S. M. e FRANCA, T. J. F. Considerações sobre os desafios da cadeia de produção de óleo de soja no Brasil, Óleos \& Grãos, p. 44, Setembro/Outubro, 1998.

[2] CAstellan. G. Physical-Chemistry, Addison Wesley Publishing Company, Inc, 1986.

[3] CHIAPPETTA, A. GIUDICI, R. e do NASCIMENTO, C. A. O. Modelagem Matemática e Simulação das Operações da Indústria de Açúcar e Álcool: II- Evaporação, Revista Brasileira de Engenharia Química, vol.9, n. 5, p. 17, 1986.

[4] CUSAK, R. W. Designing a Separation Process, Chemical Engineering, p. 128, may, 1998.

[5] FRANKS, R.G.E. Modeling and Simulation in Chimical Engineering, John Wiley \& Sons, New York, 1972.

[6] HELDMAN, D. R. \& LUND, D. B. ed. Handbook of Food Engineering, Marcel Dekker, New York, 1992.

[7] HIMMELBLAU, D. M. Engenharia Química: Princípios e Cálculos. Trad. Jossyl de Souza Peixoto, Sindicato Nacional dos Editores de Livros, Rio de Janeiro, 1984.

[8] HOLLAND, C. D. Fundamentals and Modeling of Separation Processes, Prentice-Hall, New Jersey, 1975.

[9] JONGENEELEN, H. P. J. Energy Conservation in Solvent Extration Plants, JAOCS Journal of the American Oil Chemists Society, vol.53, p. 291, June, 1976. 
[10] MCCABE, W. L., et al. Unit Operations of Chemical Engineering, McGraw-Hill, New York, 1985.

[11] PARAíso, P. R., Modelagem e Análise do Processo de Obtenção do Óleo de Soja, 2001, Tese de Doutorado - FEQ/UNICAMP.

[12] PERkins, E. G. in: Pratical Handbook of Soybean Processing and Utilization, AOCS Press and the United Soybean Board, 1995.

[13] PERRY, R. H. e CHILTON, C. H. Chemical Engineers' Handbook, 5 ${ }^{a}$ ed., $\mathrm{M}_{\mathrm{C}}$ Graw-Hill Kogakusha Ltd, Tokyo, 1973.
[14] SANDLER, S. I. Chemical and Engineering Thermodynamics, $2^{a}$ ed., John Wiley \& Sons, New York, 1989.

[15] ZANETTI, E. L. S. Industrialização da Soja. In: MIYASAKA, S. \& MEDINA, C., ed. A Soja no Brasil. Campinas, ITAL, 1981.

\section{6 - AGRADECIMENTOS}

À COAMO que disponibilizou os dados operacionais. 